This item was submitted to Loughborough's Research Repository by the author.

Items in Figshare are protected by copyright, with all rights reserved, unless otherwise indicated.

\title{
Intelligent energy management system for PV-battery-based microgrids in future DC homes
}

PLEASE CITE THE PUBLISHED VERSION

http://dx.doi.org/10.1515/ijeeps-2015-0210

\section{PUBLISHER}

(c) De Gruyter

\section{VERSION}

AM (Accepted Manuscript)

\section{PUBLISHER STATEMENT}

This work is made available according to the conditions of the Creative Commons Attribution-NonCommercialNoDerivatives 4.0 International (CC BY-NC-ND 4.0) licence. Full details of this licence are available at: https://creativecommons.org/licenses/by-nc-nd/4.0/

\section{LICENCE}

CC BY-NC-ND 4.0

\section{REPOSITORY RECORD}

Chauhan, Rajeev Kumar, Bharat Singh Rajpurohit, Francisco Gonzalez-Longatt, and Sri Niwas Singh. 2019. "Intelligent Energy Management System for Pv-battery-based Microgrids in Future DC Homes". figshare. https://hdl.handle.net/2134/23367. 


\title{
Intelligent Energy Management System for PV- Battery-based Microgrids in Future DC Homes
}

\author{
R. K. Chauhan, Senior Member, IEEE, B. S. Rajpurohit, Senior Member, IEEE, F. M. Gonzalez- \\ Longatt, Senior Member, IEEE, S.N. Singh, Senior Member, IEEE
}

\begin{abstract}
This paper presents a novel intelligent energy management system (IEMS) for a DC microgrid connected to the public utility (PU), photovoltaic (PV) and multi-battery bank (BB). The control objectives of the proposed IEMS system are: (i) to ensure the load sharing (according to the source capacity) among sources, (ii) to reduce the power loss (high efficient) in the system, and (iii) to enhance the system reliability and power quality. The proposed IEMS is novel because it follows the ideal characteristics of the battery (with some assumptions) for the power sharing and the selection of the closest source to minimize the power losses. The IEMS allows continuous and accurate monitoring with intelligent control of distribution system operations such as battery bank energy storage (BBES) system, PV system and customer utilization of electric power. The proposed IEMS gives the better operational performance for operating conditions in terms of load sharing, loss minimization, and reliability enhancement of the DC microgrid.
\end{abstract}

Keywords - Battery energy storage system, DC microgrid, distributed control, distributed generation, intelligent energy management system, power sharing.

\section{INTRODUCTION}

A microgrid consists of interconnected distributed energy resources (DER), capable of providing sufficient and continuous energy for a significant portion of internal load demand [1]. This concept easily works in both the AC and DC systems but the implementation of DC microgrid system provides several advantages in terms of redundancy, modularity, fault tolerance, higher efficiency, high reliability, easy maintenance, smaller size and lower design cost. Beside from reducing resource and financial costs, an important advantage of DC microgrid is that, it simplifies and provides the opportunity to integrate renewable energy sources (RES) that are intrinsically DC source (i.e. solar PV, small wind turbines, or fuel cells) at higher efficiency.

Most of the loads in the residential/commercial buildings are DC loads or AC loads that can be easily converted to DC loads. Hence, the DC output of the RES can be directly used within the buildings without converting to the AC to feed to the electric grid [2-3]. The PV arrays inherently generate DC power and a DC microgrid is a suitable solution to interconnect photovoltaic (PV) generation systems with public utility (PU) and loads via an inverter [4-5]. The stochastic nature of PV power and dynamic nature of demand forces the energy storage devices connected in the DC microgrid, to smoothen the power flow with high quality. At present, low voltage DC distribution systems are used only in some applications, such as telecommunication equipment with $48 \mathrm{~V}$ DC [6], traction systems [7], and shipboard systems [8].

The use of battery bank energy storage (BBES) system is a popular alternative to maximize the penetration level of variable power coming from RES to DC microgrid. The optimal operation of DC microgrid requires proper control strategies such as battery control and monitoring system (BCMS). It monitors critical conditions of battery bank (BB) and allows an early detection of outage conditions. In [9] the robustness of battery state of charge (SOC) estimation has been evaluated for varying load and temperature conditions. On the other hand in [10] an estimator (entropy-based) method is used for evaluating the capacity of Li-ion batteries used in electrified vehicles.

The monitoring system of each source plays an important role in reliability and security of the DC microgrid. The control of load sharing between PV plant and the BBES is critical issue in DC microgrid, which should be based on the sources and storage power rating and characteristics. The last one involves complexity related to the charging/discharging processes of BB. Many load-sharing techniques have been reported in the literature during the last decade. Some studies have been reported for power sharing, such as, parallel connected sources [11-12], load sharing: network method [1315], cascade load sharing method [15-16] and local control method [16-18] parallel load sharing and lumped load consideration [19-21], islanding operation [22-23] and voltage droop based power sharing method [24-25] etc. There is some literature which focuses on size optimization and power management of BB with other energy system sharing [26-27].

Energy management system (EMS) is playing an important role in DC microgrid. There are many papers with considering the different problem associated with the EMS [28-30]. In some papers [31-34], the genetic algorithm or neural network based optimization has been used for microgrid control. However there is a drawback of these type of techniques that these having no ability to welcome the new source or load. They were designed for fixed number of sources and loads. Moreover, these systems are showing the centralized controlling algorithm. The proposed IEMS system is a solution of some of these problems. The most obvious features such as voltage stability, selection of the closest source of load and approaching the ideal characteristics of source (battery) makes proposed IEMS more advance. Use of battery keeps the microgrid balancing. The current and voltage based power sharing approach of IEMS keeps the source characteristics 
very close to its ideal characteristics. Moreover, it minimizes the voltage fluctuation to keep the voltage closer to reference voltage in the microgrid. The selection of the closest source to the load feature of IEMS minimizes the power losses. On the other hand, the traditional approaches do not have all these features simultaneously. They also don't having the ability to select the nearest source according to the load requirement and availability of extra power. The proposed IEMS system can work with multi-sources and loads for lumped and distributed load.

\section{MATERIAL AND METHODS}

This section presents a detailed explanation about proposed IEMS and two types of DC microgrid configurations, which are considered for development of the IEMS: (i) Distributed energy resources with lumped load (DERLL) and (ii) Distributed energy resource with distributed load (DERDL). The DERLL configuration is designed so that BBs connected to the DC microgrid will follow its own ideal charging/discharging characteristic during power sharing. On the other hand the DERDL configuration is designed for the selection of the closest source to the load to optimize the power losses in the DC microgrid. Three energy sources (PU, $\mathrm{PV}$, and $\mathrm{BB}$ ) are considered for both configurations in this paper.

\subsection{Battery Model}

Fig. 1 showing a simplified equivalent circuit for battery with limits of no diffusion rate and accessible active site with large fraction. The resistances between the active electrode and external battery terminal are represented by resistors $R_{C C_{-} c}$ and $R_{C C_{-} a}$ respectively. While $R_{E l}$ is the electrolyte resistance. At anode and cathode interface there are double layer capacitances resistors $C_{D L_{-} a}$ and resistors $C_{D L_{-} c}$ respectively. The series combination of resistors $R_{F}$ and capacitors $C_{\phi}$ creates faradaic reaction. The values of capacitors and resistors are the function of operating parameters such as DC current, temperature and state of charge [35-36].

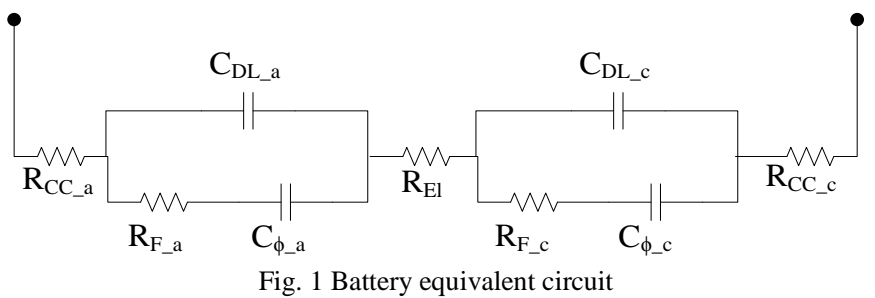

There are many phenomena's, which may affect the battery operation during charging mode. Some of them are; no fully charging of batteries with constant charging current, application of high charging currents due to which the voltage reaches to the gassing threshold so quickly, internal resistors increase the power loss and at high level SOC the thermal effect increases [37]. At the negative plate there are exothermic oxygen recombination reactions as well as $I^{2} R$ losses during the charging of battery which creates significant heating. As heating is directly proportional to the current and the generated heat increases the current and the excessive current creates a heating effect on the battery cell. The depth of previous stage discharge as well as available current for charging decides the magnitude and charging rate of the battery. The available and allowed charging current should be a function of discharge depth and limited maximum values keep the temperature rise below $10^{\circ} \mathrm{C}$ during battery recharge. The relation is shown in example as in Table 1.

Table 1 Maximum Allowable Recharge [38]
\begin{tabular}{|c|c|c|}
\hline $\begin{array}{l}\text { Approximate } \\
\text { Discharge Rate } \\
\text { and Duration }\end{array}$ & $\begin{array}{l}\text { Depth of Previous } \\
\text { Discharge } \\
\text { Rate) }\end{array}$ & $\begin{array}{l}\text { Maximum Hr. } \\
\text { Research Current per } \\
\text { 100 } \text { Ah Rated Capacity }\end{array}$ \\
\hline 15 minutes & $45 \%$ & 100 amperes \\
\hline 30 minutes & $55 \%$ & 50 amperes \\
\hline 60 minutes & $62 \%$ & 40 amperes \\
\hline 3 hours & $75 \%$ & 33 amperes \\
\hline 5 hours & $81 \%$ & 25 amperes \\
\hline 8 hours & $88 \%$ & 20 amperes \\
\hline 20 hours & $100 \%$ & 10 amperes \\
\hline
\end{tabular}

\subsection{Battery Characteristics}

Practically each battery has its own charging and discharging characteristics, as shown in Fig. 2.

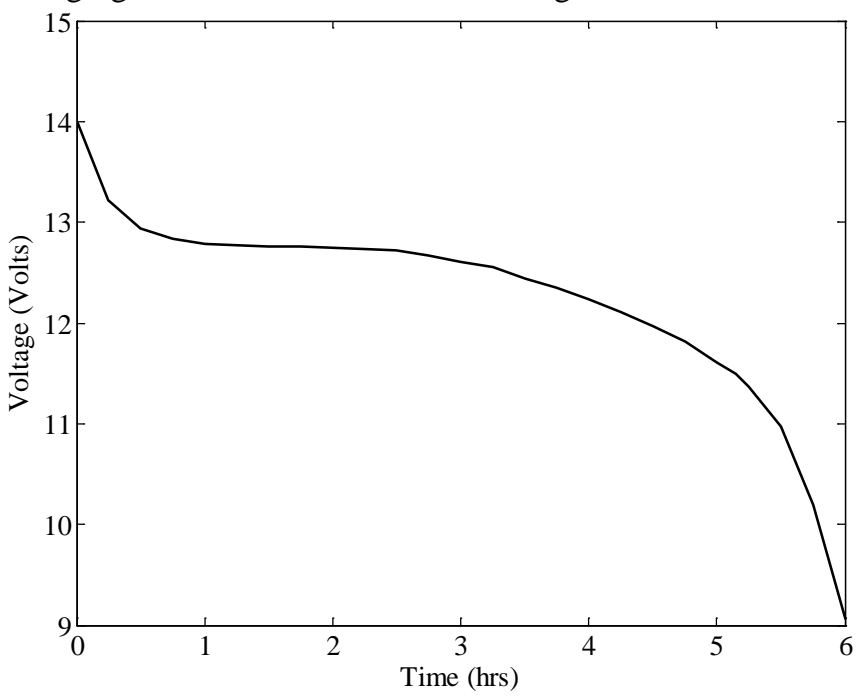

Fig. 2. Typical charging-discharging characteristics of battery bank

If the battery charging/discharging rate is not following a pattern similar to its own ideal characteristics then the battery backup time as well as the battery life may decrease. As consequence, a good load sharing mechanism of BB should be based on the battery rating and its own designed charging/discharging. At that point, empty battery will behave as a load and start charging from the DC microgrid. On the other hand, the series connection of BBs will charge the discharged batteries with reverse voltage, which may damage the battery because batteries are not designed for reverse charging [39-40]. Battery discharge characteristics (Lithium ion) may be expressed as:

$$
V=V_{0}-\lambda \frac{\mu}{\mu-i t}+\alpha e^{-\beta i t}
$$


where, $V$ is no load voltage (volt), $V_{0}$ is constant voltage (volts), $\lambda$ is polarization voltage (volt), $\mu$ is the battery capacity (Ah), $\alpha$ is exponential voltage (volt), and $\beta$ is exponential capacity (Ah) ${ }^{-1}$, it is the extracted capacity (Ah).

\subsection{Distributed Energy Resource with Lumped Load (DERLL)}

The DC microgrid is supplying a lumped load as shown in Fig. 3. The PV and PU are connected to DC microgrid via DC-DC and AC-DC converters respectively. The power sharing of BB-1 and BB-2 has been controlled using power electronics converter (PEC-1) and PEC-2 respectively. The regulation of DC microgrid voltage could be achieved by power balancing in the DC microgrid. This power balance can be attained by a correct adjustment of power contribution by AC-DC converter of PU, DC-DC converters of solar PV plant, BB-1 and BB-2. It adjusts the DC microgrid voltage at an acceptable limit during transient as well as steady state conditions. Fig. 3 shows the DERLL system having a controlling strategy of microgrid voltage and battery characteristics. The minimum selector-1 output is the function of output of Controller-1 and Controller-2. The proportional integral derivative (PID) controller has been used with the propositional gain $\left(K_{p}=0.5\right)$, integral gain $\left(K_{I}=0.001\right)$ and derivative gain $\left(K_{d}=0.00005\right)$ [43].

Controller-1 output signal $\left(\Gamma_{1}\right)$ is the function of the error generated due to reference DC microgrid voltage $\left(U_{r e f}\right)$ and actual (measured) DC microgrid voltage $\left(U_{\text {mea }}\right)$ :

$$
\Gamma_{1}=f_{1}\left(E_{\text {grid }}\right)
$$

where $E_{\text {grid }}$ is the error in microgrid voltage which is expressed as:

$$
E_{\text {grid }}=U_{\text {ref }}-U_{\text {mea }}
$$

Controller-2 output signal $\left(\Gamma_{2}\right)$ is the function of the error generated due to the standard charging/discharging current of BB-1 and the actual (measured) current (flows between BB-1 and DC microgrid):

$$
\Gamma_{2}=f_{2}\left(E_{B B 1}\right)
$$

where $\left(E_{B B 1}\right)$ is the error in BB-1 charging/discharging current and can be expressed as:

$E_{B B 1}=\phi_{S, B B 1}-\phi_{\text {mea }, B B 1}$

where $\phi_{S, B B 1}$ is the standard charging/discharging current of the BB-1 and $\phi_{m e a, B B 1}$ is the actual measured current sharing between the DC microgrid and BB-1.

Minimum selector-1 output signal $\left(\xi_{1}\right)$ is the minimum value of both of these controller outputs $\left(\Gamma_{1}, \Gamma_{2}\right)$ :

$$
\xi_{1}=\lim _{x \rightarrow 0}\left[\frac{d}{d x}\left(\Gamma_{1}(x), \Gamma_{2}(x)\right)\right]
$$

The $\xi_{1}$ signal actuates the pulse width modulator (PWM-1) to operate the PEC- 1 to adjust the minimum value to its standard value i.e. the value of $E_{B B 1}$ and $E_{\text {grid }}$ near to zero. The minimum selector-2 output signal $\left(\xi_{2}\right)$ is the minimum value of difference of output of Controller-1 and Controller-2 output and the output of Controller-3.

Controller-3 output signal $\left(\Gamma_{3}\right)$ is the function of the error generated due to the standard charging/discharging current of BB-2 and the actual (measured) current (flows between BB-2 and DC microgrid):

$$
\Gamma_{3}=f_{3}\left(E_{B B 2}\right)
$$

$E_{B B 2}$ is the error in BB-2 charging/discharging current and can be expressed as:

$$
E_{B B 2}=\phi_{S, B B 2}-\phi_{\text {mea }, B B 2}
$$

where $\phi_{S, B B 2}$ the standard charging/discharging current of the BB-2 and $\phi_{m e a, B B 2}$ the actual (measured) current sharing between the DC microgrid and BB-2.

$$
\begin{aligned}
& \text { The output of minimum selector- } 2 \text { is } \\
& \xi_{2}=\lim _{x \rightarrow 0}\left[\frac{d}{d x}\left[\left\{\Gamma_{1}(x)-\Gamma_{2}(x)\right\}, \Gamma_{3}(x)\right]\right]
\end{aligned}
$$

The $\xi_{2}$ signal actuates the pulse width modulator (PWM-2) to operate the PEC-2 to adjust the minimum value to its standard value i.e. to set the $E_{B B 2}$ near to zero.

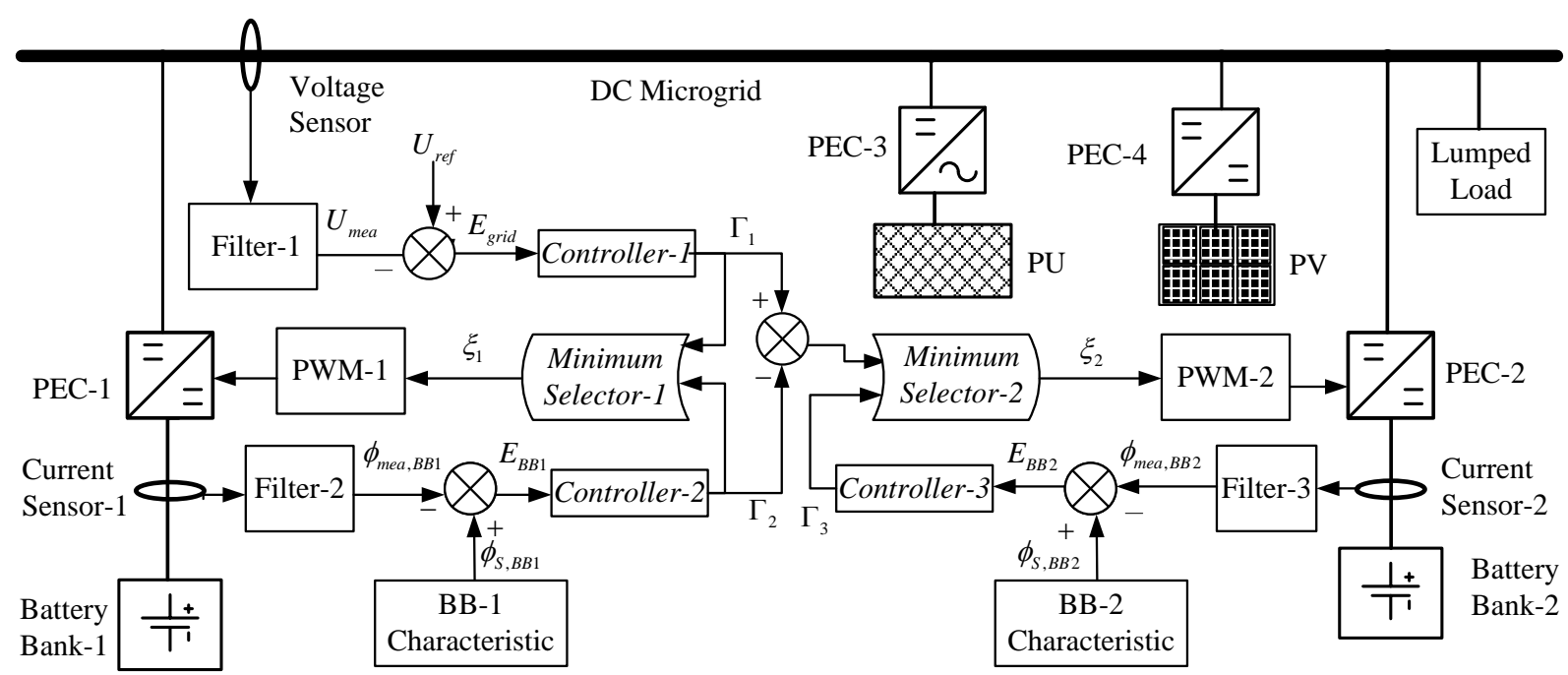

Fig. 3. Schematic diagram of distributed energy resource with lumped load (DERLL) considering proposed control strategy. 
2.4 Distributed Energy Resource with Distributed Load (DERDL)

Fig. 4 shows the schematic diagram of DC microgrid configuration including the DER with distributed load. There are four homes (Home-1, Home-2, Home-3 and Home-4) supplied by PU, DER and the BBs via DC microgrid. This is assumed that each home has own PV plant. There are four current sensors connected between power source and homes as shown in Fig. 4 . The current sensors output also act as feedback to the controllers of power source. The feedback signal $\zeta_{\text {dy }}$ from $y^{\text {th }}$ current sensor is as follows:

$$
\zeta_{d y}=\phi_{h y}-\phi_{C S y}
$$

where $y=1,2,3,4 . \phi_{h y}$ is the current consumption in $y^{\text {th }}$ home and $\phi_{c s y}$ is the current measured by the $y^{t h}$ current sensor.

The $\zeta_{d 1}, \zeta_{d 2}, \zeta_{d 3}$ and $\zeta_{d 4}$ are the error signals to active the Controller-1, Controller-2, Controller-3 and Controller-4 respectively to select the power source for the fulfillment of the required power. In this case, the controller output depends on three parameters: (i) the error signal which is basically the feedback to the controller, (ii) minimum distance between slave home (which require borrowing power from the nearest source) and master plant (which require to donate the power for other nearest homes) and (iii) power availability of the selected power source.

Mathematically the $y^{\text {th }}$ controller output $\Gamma_{d y}$ is

$$
\Gamma_{d y}=f\left(\zeta_{d y}, \Delta, \hbar\right)
$$

where $\Delta$ is the minimum distance between slave and master plant and expressed as:

$$
\Delta=\lim _{x \rightarrow 0} \frac{d}{d x}\{D(x)\}
$$

and $\hbar$ is the available load sharing capacity of master plant after fulfillment of the self requirement, and satisfies the condition

$$
\hbar \geq \zeta_{d} \geq \Psi_{h}-\Psi_{S}
$$

where $\Psi_{h}$ is the master home/plant feed power to the DC microgrid and $\Psi_{s}$ is slave home, consumed the power from the DC microgrid.

The controller helps to select the nearest source that having the sufficient power, which is more, or equal to the required power by the slave home. The controller checks all three parameters, discussed earlier in this section and continues checking until the three conditions will be satisfied.

There is minimum selector- 1 for detecting the home, which requires the extra power from other nearest home. Minimum selector-1 output $\left(\xi_{\mathrm{d} 1}\right)$ is the minimum value of both of these controller outputs $\left(\Gamma_{d 1}, \Gamma_{d 2}\right)$ :

$$
\xi_{d 1}=\lim _{x \rightarrow 0}\left[\frac{d}{d x}\left\{\Gamma_{d 1}(x), \Gamma_{d 2}(x)\right\}\right]
$$

The output $\left(\xi_{d 2}\right)$ of minimum selector-2 is the least value of the outputs $\left(\Gamma_{d 3}, \Gamma_{d 4}\right)$ of the controller-3 and controller-4 at different time instants and can be expressed as:

$$
\xi_{d 2}=\lim _{x \rightarrow 0}\left[\frac{d}{d x}\left\{\Gamma_{d 3}(x), \Gamma_{d 4}(x)\right\}\right]
$$

$\xi_{d 1}$ and $\xi_{d 2}$ actuates the PWM-1 and PWM-2 to operate the PEC-1 and PEC-2 respectively to find out the minimum value shown from both controller and helps in finding out the nearest source to the power desiring home. On the other hand the minimum selector-3 sends the signal to $\mathrm{PU}$ for desired minimum demand.

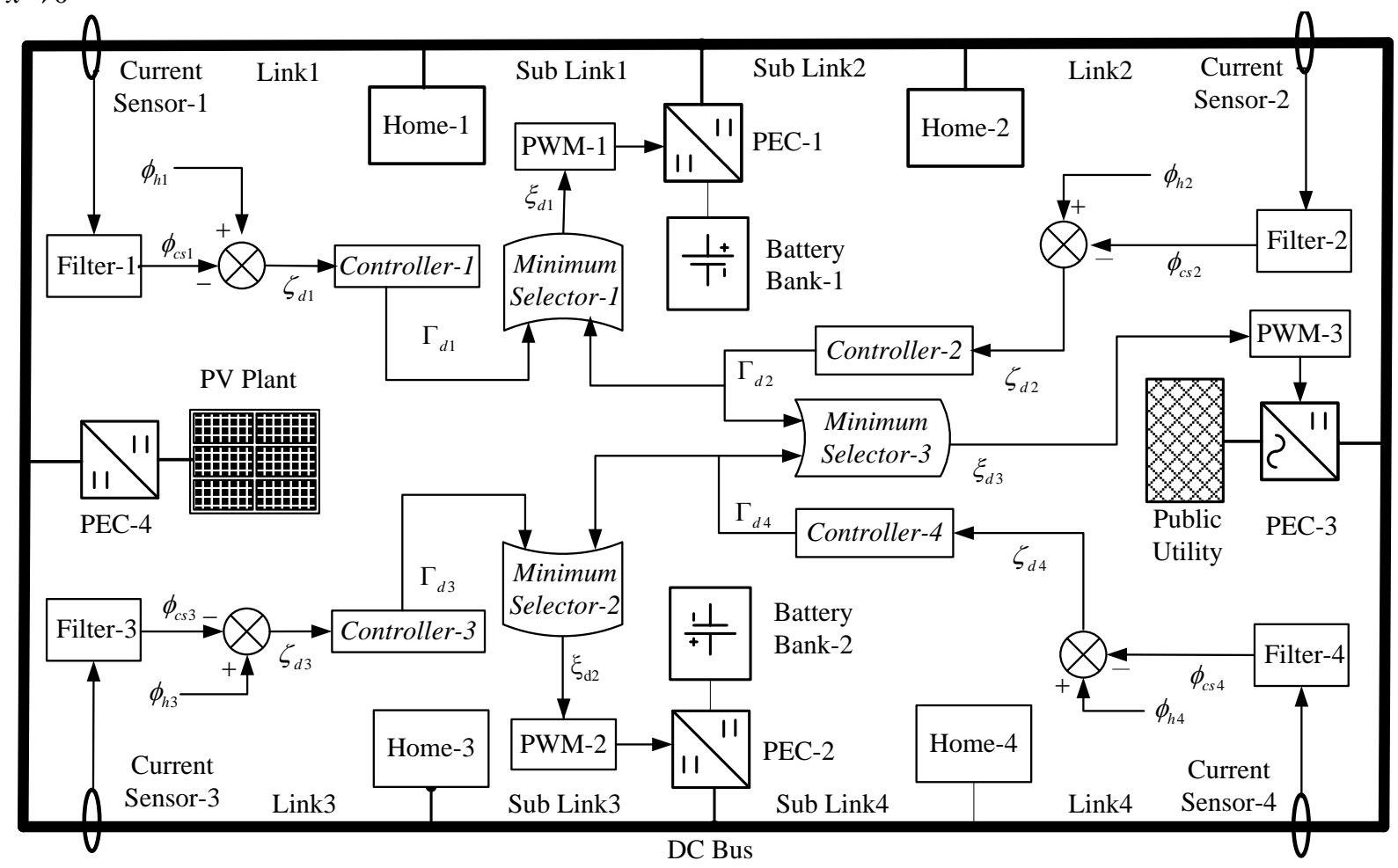

Fig. 4. Schematic diagram of DERDL considering details of the proposed control strategy for load sharing 
The minimum selector-3 output ( $\left.\xi_{\mathrm{d} 3}\right)$ is the minimum value of the outputs $\left(\Gamma_{d 2}, \Gamma_{d 4}\right)$ of the controller- 2 and controller- 4 at different time instants and can be expressed as:

$$
\xi_{d 3}=\lim _{x \rightarrow 0}\left[\frac{d}{d x}\left\{\Gamma_{d 2}(x), \Gamma_{d 4}(x)\right\}\right]
$$

$\xi_{d 3}$ sends the signal to PWM-3 to actuate the PEC-3 and fulfils the minimum power demand.

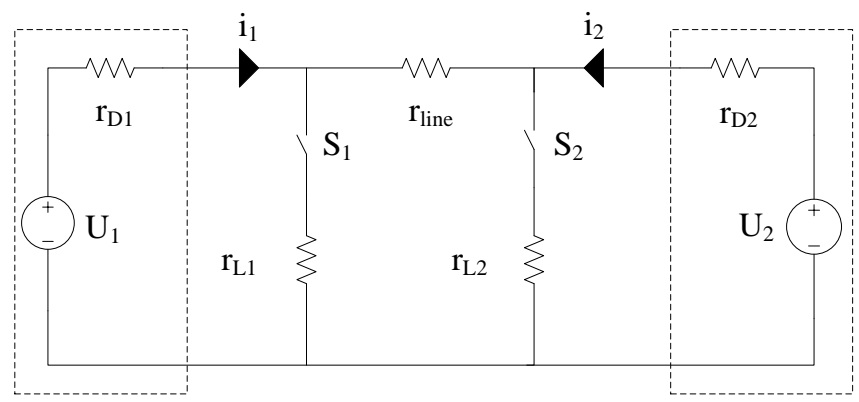

Fig.5. Two-source two-load DC microgrid.

In case of distributed load in DC microgrid, there may arise a voltage difference, which varies when the power flow across the interconnecting cables changes according to distribution load [31]. Due to dependency of the source currents on the node voltages for droop control they also depend on load distribution in the presence of resistance of the connecting cable. If the droop gain increases the deviation in source currents can be reduced but the voltage variation also increased with this. For example a two-source and two-load system is shown in Fig. 5. There are two voltage sources connected by a resistive cable and local loads connected to each source. The analysis of this circuit for distributed load is presented in results section.

\section{THEORY AND CALCULATIONS}

This section presents simulation results of the proposed IEMS for DC microgrid for a typical day in first subsection. In the next subsection the performance of the proposed IEMS (in case of lumped load) has been explained in terms of comparison with other IEMS systems. The chargingdischarging characteristic of battery bank (BB) in the proposed IEMS is compared with ideal BB characteristics. The system is compared in terms of power consumed from PU, PV and BBs. The proposed IEMS system is showing much better and managed power sharing between the power sources. After this, next section is describing the performance of proposed IEMS system (in case of distributed load). The load sharing characteristics of the proposed IEMS system has been described for voltage drop and power loss due to distributed load. The parameters of the DC bus of the microgrid can be found in the Table 2 .

\section{Table 2 DC Bus Parameters}

\begin{tabular}{|l|l|}
\hline \multicolumn{2}{|l|}{ System parameters } \\
\hline Cable cross section area & $241.9 \mathrm{~mm}^{2}$ \\
\hline Unit resistance of bus $\left(r_{u l}\right)$ & $121 \mathrm{~m} \Omega / \mathrm{km}$ \\
\hline Segment length of bus $(l)$ & $100 \mathrm{~m}$ \\
\hline System Voltage & 12 volt \\
\hline
\end{tabular}

\subsection{Implementation of the proposed IEMS for DC microgrid}

A real-time application using the proposed IEMS for DC microgrid has been simulated using MATLAB ${ }^{\mathrm{TM}}$. All simulations presented in this paper are performed using a personal computer (PC) based on Intel ${ }^{\circledR}$, Core $^{\mathrm{TM}}$ i5-3320M CPU 2.6 GHz, 4 GB RAM with Microsoft Windows 7 Professional Edition 64-bit operating system.

3.2 Mode I-Stand-alone period: During dark periods in the night, the PV system is not capable to produce electricity and also, the microgrid is assumed to be disconnected from the PU. As consequence between 00:00 and 06:00hrs the total power demanded by the loads is supplied by the BBs. The BB1 starts load sharing from 00:00hrs and BB-2 starts load sharing when the BB-1 reached at its $90 \%$ capacity.

The energy balancing equation for this operational mode can be expressed as:

$$
\sum_{j=1}^{n} P_{B B, \mathrm{j}}(k t, \mu)=\sum_{j=1}^{q} P_{\text {load }, \mathrm{j}}(k t)
$$

where $P_{\text {load,j }}(k t)$ represents power flowing from the DC microgrid to load and $P_{B B, j}(k t, \mu)$ represent the BBs power in the DC microgrid, $n$, and $q$ represents the number of $\mathrm{BB}$, and load. $\mu$ is the stored energy in BBs.

The results of the IEMS for DC microgrid simulator is showing, that during the time period of this operational mode the BB-1 and BB-2 are providing energy (discharging process). The power imported from the PU is located a zero level because during the stand-alone operational mode the power supply from grid is not providing energy.

3.3 Mode II $-P V$ and BB discharge: When the morning time reached, around 06:00hrs, solar panel starts power generation but not giving the rated power due to dull sunshine. As shown in time interval 06:00-10:10hrs and 14:40-18:30hrs. The PV power is less than the load. The DC microgrid power is balanced by PV and BBs as expressed blow

$$
\sum_{j=1}^{n} P_{B B, j}(k t, \mu)+\sum_{j=1}^{m} P_{\mathrm{PV}, \mathrm{j}}(k t)=\sum_{j=1}^{q} P_{\text {load }, \mathrm{j}}(k t)
$$

where $P_{P V, j}(k t)$ is the PV output power and $m$ is the number of PV plants.

During 06:00-10:10hrs, there is availability of PV plant power. Hence, one battery bank (BB-2) stops discharging while another (BB-1) is still going to discharge. BB-1 again starts discharging due to low power from the PV-plant during 14:40-18:30hrs. So load has been taken by the BB-1.

3.4 Mode III $-P V$ and BB charging: During 10:10-14:40hrs, the sun is brightest. PV starts power generation closer to its rated capacity. As shown in time interval 10:10-14:39hrs. The $\mathrm{PV}$ power is greater than the load and starts battery charging. The power balancing equation can be expressed as:

$\sum_{j=1}^{m} P_{P V, j}(k t)=\sum_{j=1}^{q} P_{\text {load }, j}(k t)+\sum_{j=1}^{n} P_{B B, j}(k t, \mu)$

During this duration, the power from PV plant is higher than the load so it starts charging the BB-1 after fulfillment the load requirement and BB-1sharing the power.

3.5 Mode IV -Importing from PU: During 18:30-24:00hrs, 
there is sunset (night hrs.). PU is available and BBs behaves as an outage source. The power balancing equation can be expressed as:

$P_{p u}\left(\mu, i_{l}\right)=\sum_{j=1}^{q} P_{l o a d, j}(k t)$

where $P_{p u}\left(\mu, i_{l}\right)$ represents the power flowing from the PU to the DC microgrid and $i_{l}$ represent the current of the connected load to the DC microgrid and expressed as:

$i_{l}=\sum_{j=1}^{q} i_{j}$

In this duration, the PU supply is available and takes the complete load. The PU power is approaching the same level as the load. The four operational modes allow the IEMS for DC microgrid fulfillment of the load demand. When the BBs are fully charged then the curve goes on decreasing from its maximum value to null value. The $\mathrm{BBs}$ recharging management, operational model III, is one of the most important tasks in order to get uninterrupted power supply in the critical hours of the day. In the simulations results presented of the proposed IEMS for DC microgrid, the BBs recharging has been performed during the peak hours of the PV plant i.e. during afternoon time. The grid power is not required during 00:00-19:00hrs, total load demand is covered by PV plants and BBs. When the BB of one home is completely charged after fulfilling its own demand the excess of power may be sold to the other home or to the grid.

\section{RESULTS AND DISCUSSION}

4.1 Performance Results of Proposed IEMS System in Case of Lumped Load

Similar to [41], the available set values were randomly mixed to differ the day to day load for testing the proposed system. A discrete time simulation is performed and all parameters are set at their initial values. The set of data for [41] simulation is as: There were two photovoltaic arrays (40kW each), two wind turbines ( $40 \mathrm{~kW}$ each), two batteries (30KWh nominal each) and the load data are collected on real time from industrial and residential area. The microgrid peak power was $30 \mathrm{~kW}$. There is a community PV plant of $10 \mathrm{~kW}$ and, two batteries (600 Ah, 12 volt each) and four homes including captive PV plant. The load data are collected on real time from Pecan Street Project, University of Texas at Austin, USA (home 1 demand: $5 \mathrm{~kW}$, PV plant $5 \mathrm{~kW}$, home 2: 7.5 $\mathrm{kW}$, PV plant $5 \mathrm{~kW}$, home 3: $7 \mathrm{~kW}$, PV plant $5 \mathrm{~kW}$, and home 4: $6 \mathrm{~kW}$ PV plant $5 \mathrm{~kW}$,), at Austin, USA. The microgrid peak power was $20 \mathrm{~kW}$. The demand curve from obtained from both systems is shown in Fig. (6).

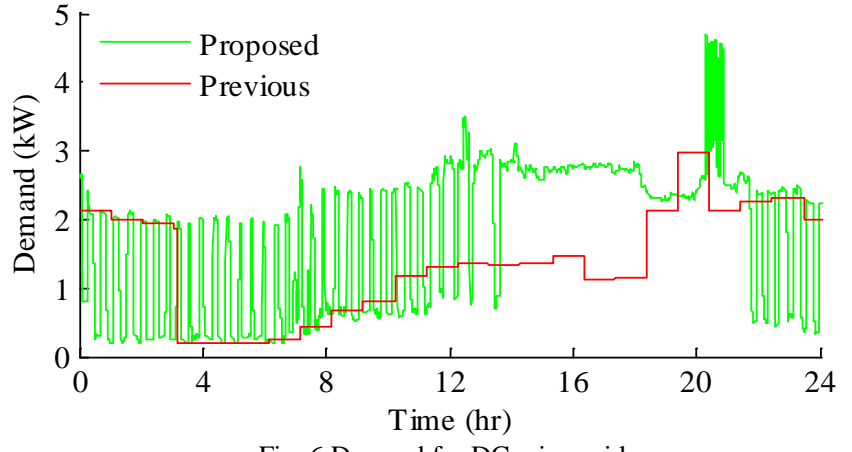

Fig. 6 Demand for DC microgrid

Fig. 7 shows a comparative analysis of proposed IEMS for DC microgrid in the form of BB performance. The data collected as the combined performance of the both BB used in the proposed IEMS for DC microgrid. As targeted, the response of charging/ discharging characteristics of BBs in the proposed IEMS for DC microgrid following the standard characteristics of battery, shown in Fig. 2, with near to zero error as the error plot in Fig. 7 is very near to zero value. Comparative to previous latest IEMS system for DC microgrid, for example [41-42], the proposed IEMS system shows better performance in terms of stability, efficiency, power losses, energy saving. In [41-42] a self-regulate system with a coherent arrangement of power sources and loads is designed to enhance the efficiency and cost. Each microgrid is having the ability to take its own decisions. There is an optimization of utilization of source according to load.

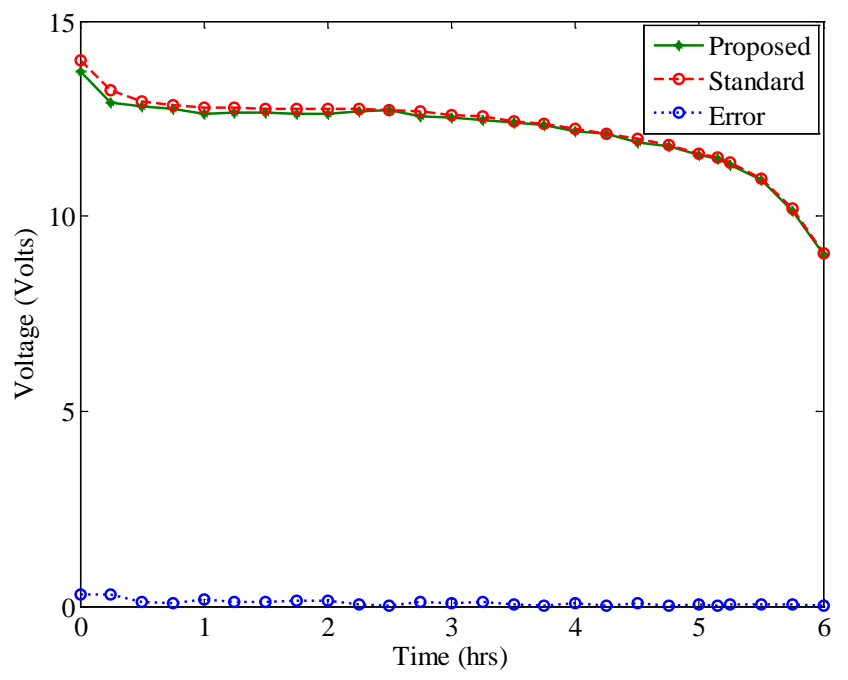

Fig. 7 Comparative analysis of battery bank characteristics

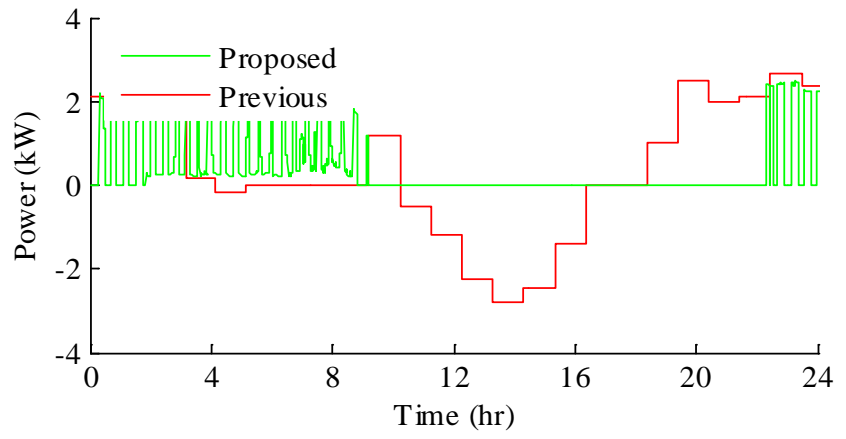

Fig. 8 Analysis of IEMS for DC microgrid in terms of PU Power 
Fig. 8 shows plots of power imported from PU during a typical 24-hour day. The plot concerned with previous IEMS [41] for DC microgrid shows that there is need to consume power in the whole day time to time. There are more fluctuations, however the plot related to the proposed IEMS for DC microgrid having a good power balancing (stability) in the DC microgrid. It shows that the proposed IEMS for DC microgrid consumes power from grid only in the night time.

Fig. 9 shows the plots of power consumed from BBs in a typical day. The plot concerned with previous IEMS system showing that there is less utilization of BBs in the typical day. The consumer has to purchase electricity from the producers according to the demand. The plot of the proposed IEMS shows an efficient utilization of BBs in the whole day. However in the day time BBs gets charged from surplus production of the PV during 08:00-17:00hrs time interval. It shows that the proposed IEMS is managed by BB and it does not need continuous (24*7hrs) PU connectivity. While in the previous scheme, the surplus $\mathrm{PV}$ production is balanced by the PU and BB gets charged by PU during the 16:00-20:00hrs time interval. It verify that the previous scheme is more dependent on the PU and needs the continuous (24*7hrs) PU connectivity.

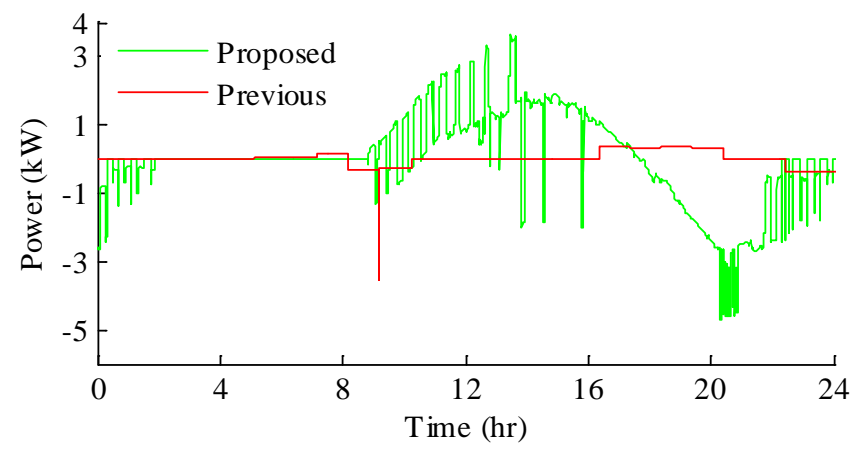

Fig. 9 Analysis of IEMS for DC microgrid in terms of BB power

The plot of power consumed from PV panels in a typical day is depicted in Fig. 10. The plot concerned with previous IEMS system shows that there is an uncontrolled charging and consumption from PV panel. During the night time and starting of the day, the $\mathrm{PV}$ is unavailable in the proposed IEMS system. As the day proceeds, the PV panel output also increases in a right manner and ends also in the same manner. The plot of the proposed IEMS shows an efficient utilization

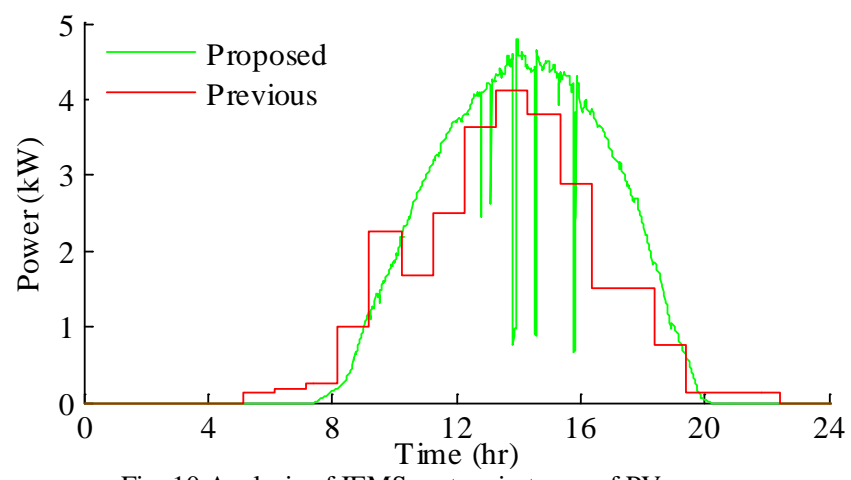

Fig. 10 Analysis of IEMS system in terms of PV power of PV panel power in the whole day. The above analysis shows the high efficiency and stability of the proposed IEMS for DC microgrid in comparison to previous available IEMS for DC microgrid [41].

\subsection{Performance Results of Proposed IEMS System in Case of Distributed Load}

The microgird consists of four homes with captive PV power plant including with one $\mathrm{PV}$ and two $\mathrm{BB}$ of the community and PU. The demand and power consumption of BB power, PU power and PV power of four homes of the microgrid for a typical day is shown in Fig. 11.
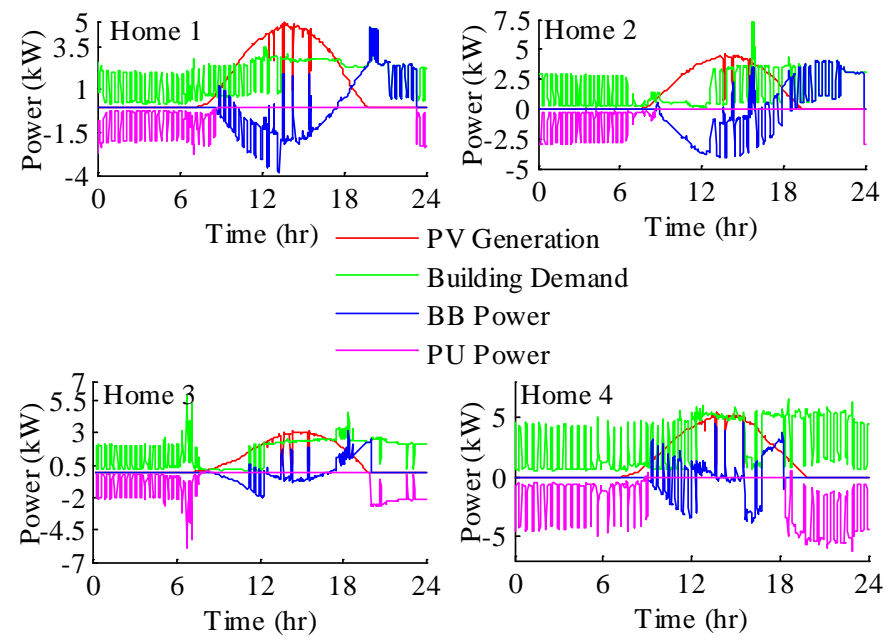

Fig. 11 Homes demand and power consumption from PV, BB, and PU

In Fig. 12, there is a voltage-current characteristic for the circuit shown in Fig. 5 by considering the analysis in [29]. The voltage axis on the graph is the voltage across load-2 and the current axis are the currents $i_{1}, i_{2}$ drawn from source- 1 and source-2, respectively. The characteristics obtained are having a slope which depends on the load to source resistance and droop gain. In this case, the low values of droop gain $r_{D 1}$ and $r_{D 2}$ leads to good voltage regulation i.e. small voltage drop; however, the current variation increases. If the value of droop gain $r_{D 1}$ and $r_{D 2}$ is high the current deviation from their ideal values is significantly lower than the previous case. However, there has an increment in voltage regulation; it is worth to say the selection of the DC voltage droop can be optimized. Moreover the voltage droop increases as the load is supplied by the far source, for example when the load-1 $\left(r_{L 1}\right)$ is switch off $\left(S_{1}\right.$ off i.e. $\left.i_{L 1}=0\right)$ and load-2 $\left(r_{L 2}\right)$ supplied by only source-2 $\left(i_{L 1}=i_{2}\right.$ and $\left.i_{1}=0\right)$ the voltage drop is minimum. On the other hand when the load-2 is supplied by source-1 $\left(i_{L 2}=i_{1}\right.$ and $\left.i_{2}=0\right)$ then the voltage drop is maximum as shown in Fig. 12. 


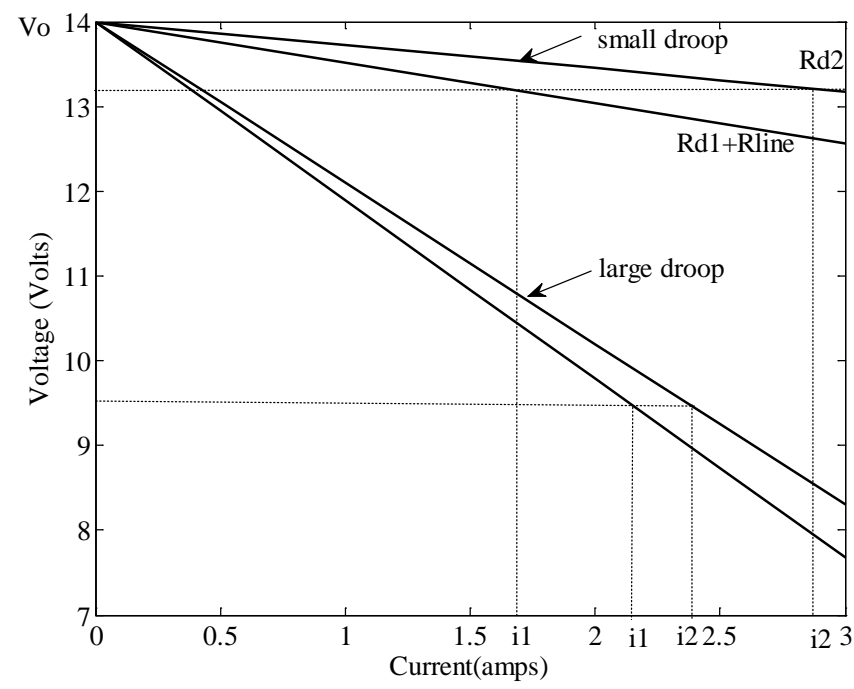

Fig. 12 Load sharing characteristics for voltage drop due distributed loads in DC microgrid.

Fig. 13 shows the power-current characteristic for the circuit shown in Fig. 5. The power axis on the graph having addition of power loss in the source gains $r_{D 1}, r_{D 2}$ and cable resistance $r_{\text {line }}$. The current axis having the current $i_{1}, i_{2}$ drowns from the source-1 and source-2, respectively. An exponential sloppy characteristic have been obtained. In this case, the power losses increase exponentially as the load is supplied by the far source. For example when the load- 1 is switch off $\left(S_{1}\right.$ off i.e. $\left.i_{l 1}=0\right)$ and load-2 supplied by only source-2 $\left(i_{L 2}=i_{2}\right.$ and $\left.i_{1}=0\right)$ the power loss is minimum. On the other hand when the Load-2 is supplied by the source-1 $\left(i_{L 2}=i_{1}\right.$ and $i_{2}=0$ ) then the system power loss is maximum as shown in Fig. 13. Further the power losses are also varying with source droop gain value $r_{D 1}$ and $r_{D 2}$. As the droop gains increase the system power loss exponentially increases. In this case the power loss increases exponentially with the increase in droop gain values $r_{D 1}$ and $r_{D 2}$ and current deviation decreases in comparison to small droop values.

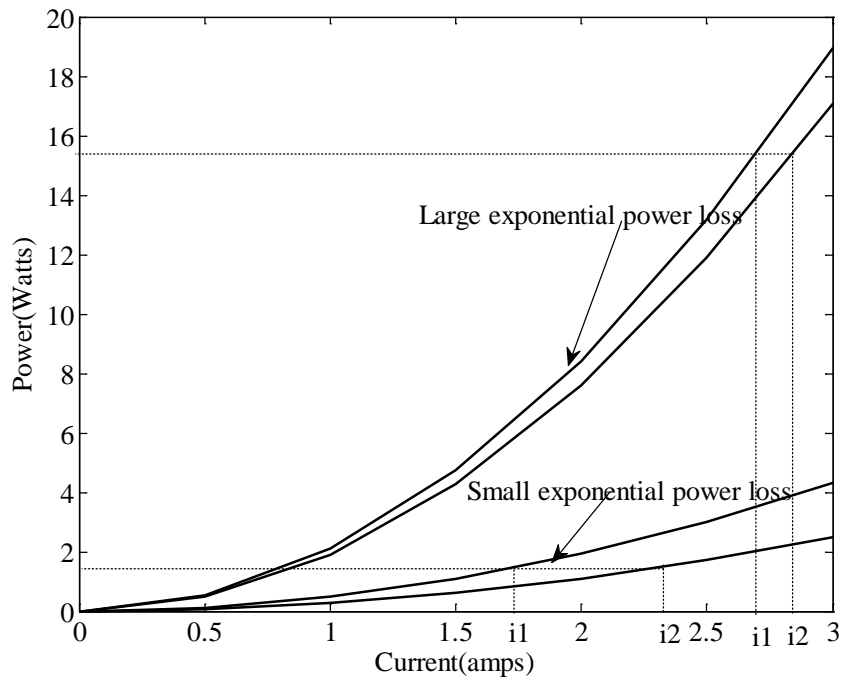

Fig. 13 Load sharing characteristics for power loss due distributed loads in DC microgrid.
The DC bus is divided into four links and four sub-links. The link1 and link3 connects the home- 1 and home- 3 to the PEC-4. Similarly link2 and link4 connects the home-2 and home-4 to the PEC-3. Moreover the sub-link1 and sub-link3 connects the home- 1 and home- 3 to the PEC-1. Similarly sublink2 and sub-link4 connects the home-2 and home-4 to the PEC-2. The length of the links and sub-links are $20 \mathrm{~m}$ and $5 \mathrm{~m}$ respectively. The microgrid power loss in the DC bus for the proposed and previous approach is calculated using Eq. (22) and shown Fig. 14.

$P_{\text {loss }}=\sum_{j=1}^{n_{l}}\left(\phi_{c s j}\right)^{2} r_{1 j}+\sum_{j=1}^{n_{s l}}\left(\phi_{c s j}-\phi_{h j}\right)^{2} r_{2 j}$

where $r_{1 j}$ and $r_{2 j}$ are the resistance of $j^{\text {th }}$ link and sub-link respectively, $n_{l}$ and $n_{s l}$ are the number of link and sub-link respectively.

When the microgrid is in PU connected mode, all the homes are feed by the PU via same path for both the approaches. During the interval 0:00-08:40 hrs, the load is feed by PU and the power loss in the buses remains same for both the approaches. During 08:41-18:20 hrs, the captive power plants (home own PV plant) generation is higher than the demand and $\mathrm{BB}$ act as load and charged by the closest $\mathrm{PV}$ plant. The closest BBs changing current circulates in the DC bus of the microgrid and power loss in the bus remains at the least level. During 18:21-23:59 hrs, the PV generation becomes zero and loads are supplied by the BBs. The loads currents are flow in the DC bus and following the different path that's why the power losses remain at the higher level during this time interval. The proposed system reduces the power losses in the bus that's why the running cost of the proposed system is get reduced.

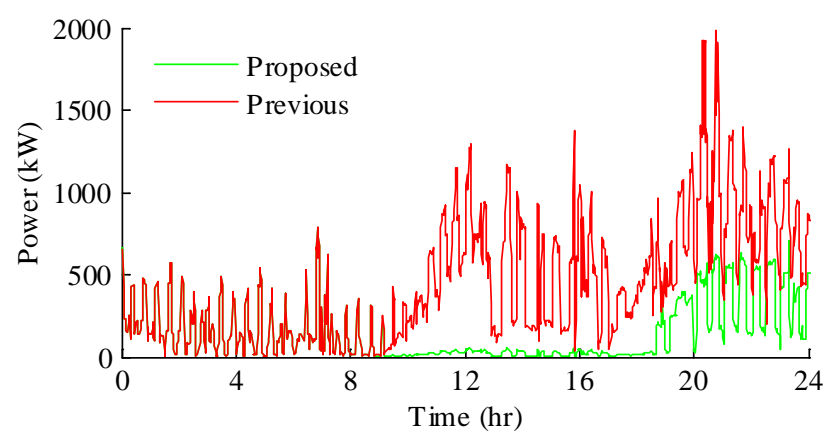

Fig. 14 Power losses in the line for distributed load with distributed generation

\section{CONCLUSIONS}

This paper proposes an intelligent energy management system (IEMS) for DC microgrids which has the ability to provide a source selection based on the priority of the closest source to the load. The distant sources have been approached only if the nearer source is not able to supply the load. This criterion will help to decrease the power loss and voltage droop in DC microgrid, as consequence, there is an intrinsic increase in the system efficiency. The proposed IEMS for DC microgrid has been designed in order to follow the charging and discharging characteristics of the battery bank (BB). It helps to ensure a longer life time and battery's performance. The used approach is very close to BB ideal characteristic 
during 00:00-06:00hrs. Real time monitoring of the stored energy in $\mathrm{BB}$ is an additional advantage of the proposed IEMS. This may be helpful to predict the future load sharing capacity of BB. At the same time, it increases the reliability and security of DC microgrid as having the knowledge about the available energy to use.

The proposed IEMS for DC microgrid has several advantages over other previous IEMS systems presented in the literature. First, there is no restriction for the number of sources and loads i.e. it is designed as a universal system. Second, it is distributed in nature. Third, there is a smart management policy exists for the BBs recharging and there is power consumption which makes the system much efficient to fulfill uninterrupted load demand. The microgrid having such advantages is very useful for the areas where the electricity supply is not regular. It is well seen that the distributed concept showing a much better solution of energy demand than the lumped system. Utilizing intelligent sensors may improve the system quality. The future research includes implementing more tests on real time basis. More intelligent instrumentation may be utilized to get optimized system in terms of efficiency and cost.

\section{REFERENCES}

[1] P. Savage, R. Nordhaus, and S. Jamieson, "DC microgrids: benefits and barriers," Yale School of Forestry and Environmental Studies, pp. 0-9, 2010.

[2] R. K. Chauhan, B. S. Rajpurohit, R. E. Hebner, S. N. Singh, and F. M. Gonzalez-Longatt, "Voltage standardization of dc distribution system for residential buildings," Jour. of Clean Energy Tech.., vol. 4, no.3, pp. 167-172, May 2016.

[3] M. R. Starke, L. M. Tolbert, and B. Ozpineci, "AC vs. DC distribution: A loss comparison," in Proc. 2008 Trans. and Dist. Conf. and Exposition, pp.1-7.

[4] R. K. Chauhan, B. S. Rajpurohit, S. N. Singh and F. M. GonzalezLongatt, "DC grid interconnection for conversion losses and cost optimization", Renewable Energy Integration: Challenges and Solutions, Springer book, pp.327-345, Sep. 2013.

[5] D. Salomonsson, and A. Sannino, "Low voltage DC distribution system for commercial power systems with sensitive electronic loads," IEEE Trans. Power Del., vol.22, no.3, pp.1620-1627, Jul. 2007.

[6] K. Mizuguchi, S. Muroyama, Y. Kuwata, and Y. Ohashi, "A new decentralized DC power system for telecommunications systems," in Proc.1990 IEEE Int. Tele Comm. Energy Conf., pp.55-62.

[7] R. J. Hill, "Electric railway traction Part 3 traction power supplies," Jour. of Power Engg., vol.8, pp.275-286, Dec.1994.

[8] J. G. Ciezki, and R. W. Ashton, "Selection and stability issues associated with a navy shipboard DC zonal electric distribution system," IEEE Trans. Power Del., vol.15, no.2, pp.665-669, Apr. 2000.

[9] X. Hu, S. Li, H. Peng, and F. Sun, "Robustness analysis of state of charge estimation methods for two types of li-ion batteries," Jour. of Power Source., vol.217, pp. 209-219, June 2012.

[10] X. Hu, S. Eben Li, Z. Jia and B. Egardt, "Enhanced sample entropybased health management of li-ion battery for electrified vehicles," Energy, vol.64, pp. 953-960, Jan. 2014.

[11] C. L. Chen, Y. Wang, J. S. Lai, Y. S. Lee, and D. Martin, "Design of parallel inverters for smooth mode transfer microgrid applications," IEEE Trans. Power Electron., vol. 25, no. 1, pp. 6-15, Jan. 2010.

[12] A. S. Ju, P. J. Woo, C. I-Yop, M. Seung-I, K. Sang-Hee, and N. S. Ryul, "Power-sharing method of multiple distributed generators considering control modes and configurations of a microgrid," IEEE Trans. Power Del., vol. 25, no. 3, pp. 2007-2016, Jul. 2010.

[13] L. Wang, H. Cheung, A. Hamlyn, C. Yang, and R. Cheung, "Network integrated protection and control strategy for power distribution systems," in Proc. 2007 Large Engg. Syst. Conf. on Power Engg., pp. 39-43.

[14] Z. Jiang, "Agent based power sharing scheme for active hybrid power sources,” Jour. of Power Source., vol. 177, no. 1, pp.231-238 Feb. 2008.
[15] T. Zhou and B. Francois, "Energy management and power control of a hybrid active wind generator for distributed power generation and grid integration,” IEEE Trans. Ind. Electron., vol. 58, no. 1, pp. 95-104, Jan. 2011

[16] L. Solero, A. Lidozzi, and J. A. Pomilio, "Design of multiple-input power converter to hybrid vehicles," IEEE Trans. Power Electron., vol. 20, no. 5, pp. 1007-1016, Sep. 2005.

[17] H. J. Chiu, H. M. Huang, L. W. Lin, and M. H. Tseng, "A multiple input DC-DC converter for renewable energy systems," in proc. 2005 IEEE Int. Conf. on Ind. Tech., pp. 1304-1308.

[18] W. Tang and R. H. Lasseter, "An LVDC industrial power distribution system without central control unit," in Proc. 2000 IEEE Power Electronic. Specialists Conf., pp. 979-984.

[19] W. Jiang, and Y. Zhang, "Load Sharing Techniques in Hybrid Power Systems for DC Microgrids" in Proc. 2011 IEEE Power and Energy Engg. Conf., pp.1-4.

[20] Y. Zhang and Z. H. Jiang, "Dynamic power sharing strategy for batteries and super capacitors hybrid energy storage system," in Proc. 2009 IEEE Vehicle Power and Propulsion Conf., pp. 558-563.

[21] W. Jiang and B. Fahimi, "Active current sharing and source management in fuel cell-battery hybrid power system," IEEE Trans. Ind. Electron., vol. 57, no. 2, pp. 752-761, Jan. 2010.

[22] I. J. Balaguer, Q. Lei, S. Yang, U. Supatti, and F. Z. Peng, "Control for grid-connected and intentional islanding operations of distributed power generation,” IEEE Trans. Ind. Electron., vol.58, no.1, pp. 147-157, Jan. 2011.

[23] J. A. P. Lopes, C. L. Moreira, and A. G. Madureira, "Defining control strategies for micro grids islanded operation," IEEE Trans. Power Syst., vol. 21, no. 2, pp. 916-924, May 2006.

[24] D. Chen, and L. Xu, "Autonomous DC Voltage Control of a DC Microgrid With Multiple Slack Terminals," IEEE Trans. Power Syst., vol. 27, no. 4, pp. 1897-1905, Nov. 2012.

[25] Q. Shafiee, J. M. Guerrero, and J. C. Vasquez, "Distributed secondary control for islanded microgrids-a novel approach," IEEE Trans. Power Electron., vol. 29, no. 2, pp. 1018-1031, Feb. 2014.

[26] X. Hu, L. Johannesson, N. Murgovski, and B. Egardt, "Longevity conscious dimensioning and power management of the hybrid energy storage system in a fuel cell hybrid electric bus.” Applied Energy, vol. 137, pp. 913-924, Jan. 2015.

[27] X. Hu, L. Johannesson, N. Murgovski, and B. Egardt, "Optimal dimensioning and power management of a fuel cell/battery hybrid bus via convex programming." IEEE/ASME Trans. Mechatronics, vol. 20, no. 1, pp. 457-468, Jul. 2015.

[28] C. Abbey and G. Joos, "Energy management strategies for optimization of energy storage in wind power hybrid system," in proc. $200536^{\text {th }}$ IEEE Power Electronics Specialists Conf. pp. 2066-2072.

[29] S. Anand, B. G. Fernandes and J. M. Guerrero, "Distributed control to ensure proportional load sharing and improve voltage regulation in lowvoltage DC microgrids," IEEE Trans. Power Electron., vol.28, no.4, Aug. 2013.

[30] A. Al-Alawi, S. M. Al-Alawi, and S. M. Islam, "Predictive control of an integrated PV-diesel water and power supply system using an artificial neural network,” Renewable Energy, vol. 32, no. 8, pp. 1426-1439, Jul. 2007.

[31] M. Cellura, G. Cirrincione, A. Marvuglia, and A. Miraoui, "A wind speed spatial estimation for energy planning in Sicily: a neural kriging application,” Renewable Energy, vol. 33, no. 6, pp. 1251-1266, Jun. 2008.

[32] D. Goa, Z. Jin, and Q. Lu, "Energy management strategy based on fuzzy logic for a fuel cell hybrid bus”, Jour. of Power Source., vol. 185, no. 1, pp. 311-317, Oct. 2008.

[33] A. Hajizadeh and M. A. Golkar, "Intelligent power management strategy of hybrid distributed generation system," Int. Jour. of Electrical Power and Energy System, vol. 29, no. 10, pp.783-795, Dec. 2007.

[34] K. S. Jeong, W. Y. Lee, and C. S. Kim, "Energy management strategies of a fuel cell/battery hybrid system using fuzzy logics," Jour. of Power Source., vol. 145, no. 2, pp. 319-326, Aug. 2005.

[35] T. Sritharan, "Impact of current waveforms on battery behavior," Dept. of Elect. and Comp. Engg., Univ. of Toronto, 2012, pp. 1-95.

[36] B.E. Conway, "Transition from super capacitor to battery behavior in electrochemical energy storage," Jour. of the Electrochemical Society, vol. 138, no. 6, pp. 1539-1548, Aug. 1990.

[37] A. M. Dizqah, A. Maheri, K. Busawon, and A. Kamjoo, "A multivariable optimal energy management strategy for standalone DC 
microgrids,” IEEE Trans. on Power Syst., vol.30, no.5, pp. 2278-2287, Sept. 2015.

[38] "Thermal Runaway in VRLA Batteries-Its Cause and Prevention," 417944, Technical Bulletin, C and D Technologies, Blue bell, PA, 2012, pp. 1-14.

[39] W.B. Gu,C.Y. Wang, S.M. Li, M.M. Geng and B.Y. Liaw, "Modeling discharge and charge characteristics of nickel-metal hydride batteries" Electrochimica Acta vol.44, no.25, pp. 4525-4541, Aug. 1999.

[40] P. Blaine, and J. Newman. "Modeling of nickel-metal hydride batteries" Jour. of the Electrochemical Society, vol.144, no.11, pp. 3818-3831, Nov. 1997.

[41] M. Cirrincione, M. Cossentino, S. Gaglio, V. Hilaire, A. Koukam, M. Pucci, L. Sabatucci, and G. Vitale, "Intelligent energy management system," in Proc. $20097^{\text {th }}$ IEEE Int. Conf. on Ind. Informatics, pp. 232237.

[42] W. Jiang, and Y. Zhang, "Load sharing techniques in hybrid power systems for DC microgrids," in Proc.2011 IEEE Asia Pacific Conf. on Power and Energy, pp. 1-4.

[43] R. K. Chauhan, B. S. Rajpurohit, R. E. Hebner, S.N. Singh and F.M.G. Longatt, "Design and Analysis of PID and Fuzzy-PID Controller for Voltage Control of DC Microgrid,” in Proc. 2015 IEEE PES Innovative Smart Grid Technologies Asian Conf., pp. 1-6.

\section{ACKNOWLEDGEMENT}

Authors are thankful to Center for Electromechanics, University of Texas at Austin for providing data from "Pecan Street Project". Authors are also thankful to DST-UKIERI for financial support.

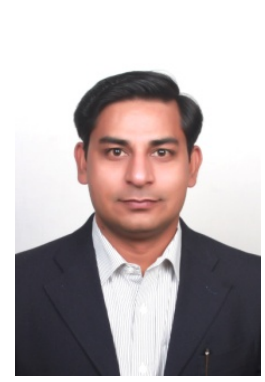

\section{BIOGRAPHIES}

Rajeev Kumar Chauhan (M'10-SM'2015) graduated in Electrical Engineering from The Institutions of Engineers (India). He received his M. Tech degree in Control and Instrumentation Engineering from Dr. B. R. Ambedkar National Instiute of Technology Jalandhar, India. Presently, he is pursuing Ph.D from School of Computing and Electrical Engineering, Indian Institute of Technology Mandi, India. Mr. Chauhan also received the Bhaskar Advanced Solar Energy (BASE-2014) fellowship from the Department of Science (DST) and Technology and Indo-US Science and Technology Forum (IUSSTF) and worked as Visiting Scientist in the Center for Electromechnics at University of Texas at Austin, US. His employment experience includes Krishna Engineering College GZB, Galgotias College of Engineering and Technology Greater Noida, Roorkee Institute of Technology Roorkee. His major field of interest included DC Microgrid, SCADA System, Industrial Automation and Control. He is the member of PES, IEEE, IET, IAENG Hong Kong and ICASIT. Mr. Chauhan is a Reviewer of the IEEE Transaction of Industrial Electronics, IEEE Transaction of Sustainable Energy, IEEE Systems Journal, Renewable \& Sustainable Energy Reviews.

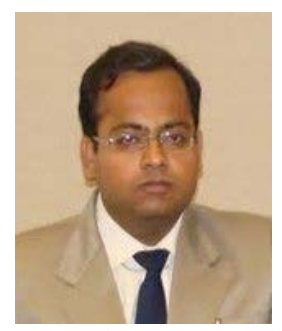

Bharat Singh Rajpurohit (M'09-SM'14) received M. Tech. from the Indian Institute of Technology Roorkee, India and Ph.D from Indian Institute of Technology Kanpur, India. Presently, he is working as Associate Professor in the School of Computing and Electrical Engineering at Indian Institute of Technology Mandi, India. Dr. Rajpurohit also received BASE-2015 fellowship from the Department of Science (DST) and Technology and Indo-US Science and Technology Forum (IUSSTF) and Visiting Faculty in the Department of Electrical Engineering at the University of Wisconsin-Milwaukee, Wisconsin. His research interests include power electronics and grid integration of renewable energy sources. He is a member of ISTE.

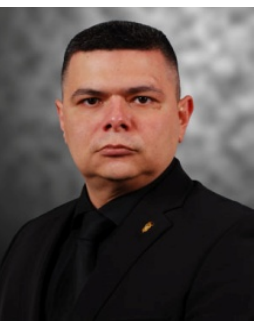

Francisco M. Gonzalez-Longatt (S'98-M'00SM'08) is currently a Lecturer in Electrical Power System at Electrical Power System en School of Electronic, Electrical and Systems Engineering en Loughborough University. His academic qualifications include first Class Electrical Engineering of Instituto Universitario Politécnico de la Fuerza Armada Nacional, Venezuela (1994), Master of Business Administration (Honors) of Universidad Bicentenaria de Aragua, Venezuela (1999) and PhD in Electrical Power Engineering from the Universidad Central de Venezuela (2008). He is former associate professor (1995-2009) and Chair (1999-2001) of the Department of Electrical Engineering of Universidad Nacional Politécnico de la Fuerza Armada Nacional, Venezuela (1995-2009). He is the author or editor of several books (Spanish and English) including "Power Factory Applications for Power System Analysis", Springer (2014 He is Vice-President of Venezuelan Wind Energy Association, Senior Member of the Institute of Electrical and Electronic Engineering (IEEE), member of The Institution of Engineering and Technology - The IET (UK) and member of International Council on Large Electric Systems -CIGRE. He received the professional recognition as FHEA - Fellow of the Higher Education Academy in January 2014. His research interest includes innovative (operation/control) schemes to optimize the performance of future energy systems. His research is or has been supported by Royal Society -UK. Two special research projects financially supported by the Royal Society deserve mention: "Smart Multi-Terminal DC microgrids for autonomous Zero-Net Energy Buildings" and "Exploring Beyond the Frontiers to Build a Smarter Grid (EBF2BSG)”.

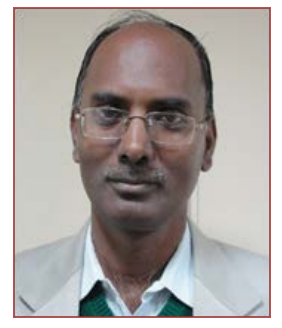

S. N. Singh (SM'02) received the Ph.D. degree in electrical engineering from the Indian Institute of Technology Kanpur, India, in 1995. He is currently a Professor with the Department of Electrical Engineering, Indian Institute of Technology Kanpur. His research interests include power system restructuring, FACTS, power system optimization and control, security analysis, and power system planning. Dr. Singh is a Fellow of the IETE, India, and the Institution of Engineers, India. 